\title{
Brave new world: the AUTP survey of academic psychiatry
}

\author{
S. W. LEwIS, Honorary Secretary AUTP, Charing Cross and Westminster Medical \\ School, St Dunstan's Road, London W6 8RP; A. C. BROWN, Outgoing Honorary \\ Secretary AUTP, Department of Mental Health, 41 St Michael's Hill, Bristol \\ BS2 8DZ; and G. F. Russell, Chairman AUTP, Institute of Psychiatry, \\ De Crespigny Park, Denmark Hill, London SE5 8AF
}

This brief article reports the results of a questionnaire survey of Academic Departments of Psychiatry in the UK in August 1992 initiated by the Association of University Teachers of Psychiatry (AUTP). The survey was undertaken in an effort to gauge more objectively a growing sense of anxiety within academic psychiatry, whose key functions - education, training, clinical research - seemed to many to be threatened by changes in the logistics of funding within universities and the NHS. These changes include the introduction of the internal market in the NHS, changes in the funding from the Universities Funding Council (UFC) and the service increment for teaching and research (SIFTR), ever stiffer competition for research grants, changing funding patterns for clinical research with the Peckham initiative, and, for the ten London departments, the Tomlinson report.

\section{The study}

This survey aimed to document changes over the previous three years in the resources generally of academic departments of psychiatry; changes in access to clinical resources for teaching and research, in particular academic in-patient beds; changes in numbers of academic staff; and opinions of heads of university departments of effects of recent and forthcoming NHS changes with regard to the practice and status of academic psychiatry. A 21 item questionnaire was mailed to all heads of university departments of psychiatry in the UK in August 1992.

\section{Findings}

Out of 29 departments, $27(93 \%)$ responded. These were Aberdeen, Birmingham, Bristol, Cambridge, Dundee, Edinburgh, Glasgow, Keele, Leeds, Leicester, Liverpool, Manchester, Newcastle, Nottingham, Oxford, Queens Belfast, Sheffield, Southampton and, in London, Charing Cross and Westminster, Kings, London, Maudsley (SHA), Royal Free, St Bartholomew's, St George's, UMDS (GuysSt Thomas'), and University College and Middlesex.
TABLE I

Results of changes in funding

\begin{tabular}{lccc}
\hline & Improved & No change & Worsened \\
\hline NHS & 7 & 8 & 12 \\
UFC funding* & 3 & 6 & 17 \\
Research funding* & 10 & 10 & 6 \\
\hline
\end{tabular}

* No reply from one department.

Several areas of responses are summarised below.

\section{Resources generally}

Respondents were asked whether, over the previous three years (July 1989 - July 1992), the resources of the Academic Department had generally improved or worsened with the result of changes in NHS, UFC funding, and research funding (Table I).

Thus, there was a wide variety of experience between departments although most reported worsened resources as a result of decreased UFC funding. Only two of the 27 departments reported resources to be unchanged in all areas, only one reported improvements in all areas and three reported worsening in all areas, giving a picture of general change. The reduction in UFC funding seemed to be offset by an increase in research funding, particularly in London departments where this had increased in the majority.

\section{Access to clinical resources}

Respondents were asked about academic bed resources and the ease of admission of nonemergency, non catchment area patients. Over the past three years the number of academic beds was reported to have increased in one department, stayed unchanged in eight departments and decreased in 13 departments. In only one unit were bed closures noted to have been undertaken as part of a constructive redeployment of services into the community. In 
two of the departments the decrease was in excess of $50 \%$. Half of the departments reported that it had become less easy to admit non-catchment, nonemergency patients. This was particularly so in London where six of the eight departments reported it was now less easy than three years ago to admit elective patients. Five of these departments rated the ease of admission of non-emergency or noncatchment patients as "impossible".

Academic units often include specialty beds for treatment of particular disorders on a supra-district basis. Two specialities in particular had lost beds over the past three years: neuropsychiatry and liaison psychiatry. Bed numbers for behavioural therapy, psychotherapy, eating disorders and others had changed only slightly.

\section{Levels of clinical academic staffing}

This did not seem adversely to be affected overall. Three departments reported a loss of UFC-funded posts, with eight departments reporting a gain. One department reported a loss of NHS-funded clinical academic posts with 13 departments reporting a gain. Seven departments reported a gain in research-grant funded posts.

\section{The future}

The final part of the questionnaire was unstructured. Respondents were asked to comment on, first, whether local NHS management was sympathetic towards academic psychiatry. In only two cases were management considered not to be sympathetic; 15 respondents felt management were generally sympathetic, and nine respondents noted a sympathetic attitude within constraints.

Next, respondents were asked to give their opinions about the effects of changes in NHS resources and university funding had had on the functioning of their departments over the previous three years. Most responses were critical; the comments elicited most frequently (four or more departments) concerned changes for the worse in three particular areas: increased administrative burden, increased burden of NHS service work, and increasingly low morale. On the last point, respondents noted "a general and justified pessimism", "life has become uniformly unpleasant", "relationship (between NHS and academic staff) is now almost at breakdown point".

Thirdly, respondents were asked to predict the nature of changes which were likely over the forthcoming three years. Responses here were pessimistic in all but five cases. Spontaneous comments included: "difficult to see how we can continue to be all things to all men"; "a great uncertainty ahead"; "very grave feelings"; "apprehensive"; "the organisation of academic medicine will change radically"; "closure of all specifically academic activity"; "complete loss of research beds"; "changes in the NHS and university are greatly to the disadvantage of academic psychiatry"; "dire". The most frequent comments (four or more departments) fell into four areas: increasing constraints on teaching, including an uncertainty about the future of undergraduate teaching and a likely retreat from the role of academic psychiatry in postgraduate teaching and training; continuing reduction in research arising out of further funding restrictions, loss of academic beds and less research time; greater NHS service pressures eroding time for academic responsibilities; and increasingly low morale with likely drop in recruitment to academic psychiatry.

\section{Comment}

Change in the patterns of funding within the NHS and universities was reported in all academic departments of psychiatry. Numbers of clinical academic staff had not in general fallen. A major area of concern was the curtailment of those areas of teaching and research which were dependent on patients. One half of the departments reported a drop in the number of academic beds and increasing difficulty in taking, as in- and out-patient, non-urgent, out-ofcatchment patients. This problem was most marked in London. Subspeciality beds without regional protection had been lost. Departments noted increased administrative burdens and low morale, and predicted increasing constraints on research time and resources with an inevitable fall in recruitment to academic psychiatry.

It was clear from the responses that NHS changes were seen as the main threat to the future of academic psychiatry. The internal market was regarded as having a major effect on the throughput of patients, leading to constraints on clinical teaching for undergraduates, and making clinical research very difficult. Sadly, many respondents also noted an increasing sense of division between academic and NHS colleagues as the old "knock for knock" agreement between universities and provider units is superseded. This snapshot of opinion shows much unease in high circles. Whether this represents the whingeing of a privileged intellectual elite at last being forced to face reality or a realistic prediction of the likely demise of psychiatric teaching and research remains to be seen. 